\title{
Poly(ester sulphonic acid) coated mercury thin film electrodes: characterization and application in batch injection analysis stripping voltammetry of heavy metal ions
}

\author{
Christopher M.A. Brett ${ }^{\mathrm{a}, *}$, Denise A. Fungaro a,b \\ a Departamento de Química, Universidade de Coimbra, 3049 Coimbra, Portugal \\ ${ }^{\mathrm{b}}$ Instituto de Pesquisas Energéticas e Nucleares (IPEN), Divisão de Química, Ambiental-MQA, Travessa ' $R$ ' no. 400, \\ Cidade Universitária, CEP 05508-900 São Paulo-SP, Brazil
}

Received 18 March 1999; received in revised form 9 July 1999; accepted 23 July 1999

\begin{abstract}
Mercury-thin film electrodes coated with a thin film of poly(ester sulphonic acid) (PESA) have been investigated for application in the analysis of trace heavy metals by square wave anodic stripping voltammetry using the batch injection analysis (BIA) technique. Different polymer dispersion concentrations in water/acetone mixed solvent are investigated and are characterised by electrochemical impedance measurements on glassy carbon and on mercury film electrodes. The influence of electrolyte anion, acetate or nitrate, on polymer film properties is demonstrated, acetate buffer being shown to be preferable for stripping voltammetry applications. Although stripping currents are between 30 and $70 \%$ less at the coated than at bare mercury thin film electrodes, the influence of model surfactants on stripping response is shown to be very small. The effect of the composition of the modifier film dispersion on calibration plots is shown; however, detection limits of around $5 \mathrm{nM}$ are found for all modified electrodes tested. This coated electrode is an alternative to Nafion-coated mercury thin film electrodes for the analysis of trace metals in complex matrices, particularly useful when there is a high concentration of non-ionic detergents. (C) 2000 Elsevier Science B.V. All rights reserved.
\end{abstract}

Keywords: Poly(ester sulphonic acid) modified electrodes; Mercury thin-film electrode; Batch injection analysis; Anodic stripping voltammetry

\section{Introduction}

The protection of electrode surfaces against interferents which block the electrode by irreversible adsorption is extremely important in the

\footnotetext{
* Corresponding author. Tel./fax: + 351-239-835295.

E-mail address: brett@ci.uc.pt (C.M.A. Brett)
}

analysis of untreated environmental samples, such as effluents. The electrochemical batch injection analysis (BIA) technique [1,2] using polymer modified electrodes is useful in this regard, since blocking problems are reduced by the small contact time between sample and electrode, samples, usually of volume $50 \mu \mathrm{l}$, being injected directly over the electrode. This approach has been ex- 
plored for the analysis of heavy metal ions by anodic stripping voltammetry [3] at cation-exchange polymer coated mercury thin film electrodes (MTFEs) [4,5] and with size exclusion polymer coatings [5]. Detection limits are slightly higher than in continuous flow systems at around $5 \mathrm{nM}$ for zinc, cadmium, lead and copper ions. Cation exchange polymers investigated were Nafion [4] and mixtures of Nafion with other sulphonated polymers [5]. It was found that there was a slightly superior performance from Nafion/ poly(vinyl sulphonic acid) (Nafion/PVSA) films with respect to discrimination against concentrations up to $20 \mathrm{mg} \mathrm{dm}^{-3}$ of model surfactants: Triton-X-100 detergent; sodium dodecylsulphate polyelectrolyte and protein standard [5]. Size exclusion polymers investigated were based on cellulose acetate [5]; the major problem with these was the fragility of the films, so they were not pursued further.

A different type of sulphonate polymer with some similar cation-exchange characteristics as Nafion is poly(ester sulphonic acid) (PESA) also known as Eastman-AQ. This polymer exists as AQ55, AQ38 and AQ29 with equivalent weights of 1500,2500 and 2500, respectively [6]. The complete structure is not known but in all cases the cation-exchange character is due to a sulphonate group in the 5-position on an aromatic ring, the polymer chain being through the 1 and 3 positions by links to ester $\left(-\mathrm{CO}_{2}-\right)$ groups [6]. Coatings of this polymer show good substrate adhesion. It has been shown that PESA-modified electrodes permit the exchange of cations for trace analysis [7], and that they discriminate well against electrode fouling [8]. Differential pulse anodic stripping voltammetry at PESA-coated mercury thin film electrodes (PCMTFE) in the presence of surfactants has also been demonstrated [9]. Further successful applications have been as ion-exchanger in acetonitrile solutions [6], and mixing with an enzyme as modifier layer [10-12] or to protect an enzyme-polymer modifier layer against external interferents [13].

The objective of this paper is to investigate the properties of PCMTFEs for application in batch injection analysis with square wave anodic stripping voltammetry (BIA-SWASV). The character- istics of the formed films are probed by electrochemical impedance techniques. Discrimination against model surfactants is investigated.

\section{Experimental}

The BIA cell was as described previously [2]. A glassy carbon disc electrode, diameter $5 \mathrm{~mm}$, is fixed directly under the tip of a programmable, motorised, electronic micropipette (Rainin EDPPlus 100) at a distance of $2-3 \mathrm{~mm}$. The internal diameter of the micropipette tip was $0.47 \mathrm{~mm}$ and a calibrated dispension rate of $24.5 \mu 1 \mathrm{~s}^{-1}$ was used in experiments to be described. The cell also contains a platinum foil auxiliary electrode and a saturated calomel electrode (SCE) as reference, and is filled with $\sim 40 \mathrm{~cm}^{3}$ of inert electrolyte.

Voltammetric experiments were controlled by a BAS CV-50W voltammetric analyser. Impedance spectra were recorded using a Solartron 1250 Frequency Response Analyser coupled to a Solartron 1286 Electrochemical Interface, controlled by a personal computer with Zplot software. A sinusoidal voltage perturbation of rms amplitude 10 $\mathrm{mV}$ was applied, scanning from $65 \mathrm{kHz}$ to $0.1 \mathrm{~Hz}$ with 5 measurements per decade of frequency, and signal auto-integration ( $t$-test at $99 \%$ confidence level) up to $50 \mathrm{~s}$.

All reagents were of analytical grade and solutions were prepared using Millipore Milli-Q ultrapure water (resistivity $>18 \mathrm{M} \Omega \mathrm{cm}$ ). Electrolytes employed included $0.1 \mathrm{M} \mathrm{KNO}_{3} / 5 \mathrm{mM} \mathrm{HNO}_{3}$ and $0.1 \mathrm{M}$ acetate buffer ( $\mathrm{pH} 4.6)$. Experiments were done at temperatures of $\left(25 \pm 1{ }^{\circ} \mathrm{C}\right)$ without deaeration.

A small quantity of solid PESA (Eastman AQ55) was a kind gift from Professor J. Pingarron, Universidade Complutense de Madrid, Spain.

\subsection{Preparation of the GC electrode coated with PESA}

Water/acetone solvent in the ratio $1: 2$ or $5: 1$ ( $\mathrm{v} / \mathrm{v})$ was added to a known mass of solid PESA to obtain a dispersion with final concentration of 0.93 or $0.25 \%$. It has been noted previously that it 
is only possible to make dispersions of this polymer e.g. [8]. It was attempted to make true solutions with a number of solvents, but without success. The glassy carbon electrode was covered with polymer by applying $10 \mu \mathrm{l}$ of the dispersion to the surface with a micropipette. After evaporating the solvents with a jet of air at room temperature, whilst the electrode was rotating at $50 \mathrm{rpm}$, the polymer film was cured with a jet of warm air at $70^{\circ} \mathrm{C}$ for about $1 \mathrm{~min}$.

\subsection{Preparation of the PESA-coated mercury thin film electrode}

In order to prepare the PCMTFE, the PESAmodified electrode was placed in a BIA cell [2] and mercury deposition was done in situ by injection of $10 \mu \mathrm{l}$ of $0.1 \mathrm{M} \mathrm{Hg}$ (II) in $0.1 \mathrm{M} \mathrm{KNO}_{3} / 5 \mathrm{mM}$ $\mathrm{HNO}_{3}$ directly over the centre of the electrode, applying a potential of $-1.0 \mathrm{~V}$ during $64 \mathrm{~s}$ [5].

\section{Results and discussion}

The results to be described used three different polymer solutions for electrode coatings. This is because PESA does not form a true solution, as mentioned in the experimental section; it is only possible to make a dispersion. Water and acetone solvent mixtures were employed: in the first two of these the water/acetone ratio was $1: 2$, the concentrations of PESA being 0.93 and $0.25 \mathrm{wt} \%$ in order to investigate the effect of concentration on polymer solubility. In the third, the water/acetone ratio was $5: 1$, with a $0.25 \mathrm{wt} \%$ concentration of PESA. The identity and ratio of the solvents can influence the morphology of the film obtained and the re-formation of the crystalline phases of the polymer. Most studies in the literature describe dispersions in the range $1-1.5 \mathrm{wt} \%$ concentration [6-9], higher than those used here. Nevertheless, the aim in this work was to produce a reproducible film as thin as possible.

\subsection{Characterisation of the modified electrodes}

The films formed were homogeneous and opaque with no visible differences between the three types of prepared film. Film thickness was estimated by optical microscopy as $1 \mu \mathrm{m}$ for application of $10 \mu \mathrm{l}$ of polymer dispersion. The PCMTFEs also showed a visually uniform formation of mercury over the entire electrode surface. Preliminary experiments showed that they could be used for BIA-SWASV - see Fig. 1 for examples, which also demonstrates that some difference in stripping response at the various types of PESA-modified electrode is observed.

Further characterisation of the films of PESA on the glassy carbon substrate and of the polymercoated MTFEs was done using electrochemical impedance in acetate buffer and nitrate electrolyte solutions. The reason for the choice of two electrolytes was that previous work on Nafion-coated electrodes has shown that there is a possible influence from the identity of the electrolyte anion, but not the cation [5]. Fig. 2 shows some typical impedance spectra in the complex plane for a PESA film formed from a $0.93 \%$ concentration dispersion in 1:2 water/acetone solvent, without deaeration of the solution. Several points can be readily deduced. At $0.0 \mathrm{~V}$ there is little evidence of charge transfer processes, the capacitive response being reduced by film roughness and porosity effects [14] (this is also observed at bare glassy carbon electrodes [15]). At applied potentials of -0.5 and $-1.0 \mathrm{~V}$ the curvature in the plots can be attributed to oxygen permeating through the polymer film and possibly reduction of the carbon surface itself, as confirmed by experiments in the absence of dissolved oxygen. The influence of the anion identity is significant at $-0.5 \mathrm{~V}$. At more negative potentials, as is observed at $-1.0 \mathrm{~V}$, this difference would be expected to be less owing to the negative anionic charge. Similar observations of the permeation of nitrate anion have been made at Nafion membranes, where the cation exchange behaviour is also due to sulphonate groups [16].

Impedance plots at the PCMTFE at -0.5 and $-1.0 \mathrm{~V}$ are shown in Fig. 3. At $-1.0 \mathrm{~V}$ the spectra exhibit a similar behaviour to Fig. 2 without mercury. However, at $-0.5 \mathrm{~V}$ there is evidence of a charge transfer process, ascribed to oxygen reduction, verified by removing oxygen, and the impedance values for oxygen reduction are much 

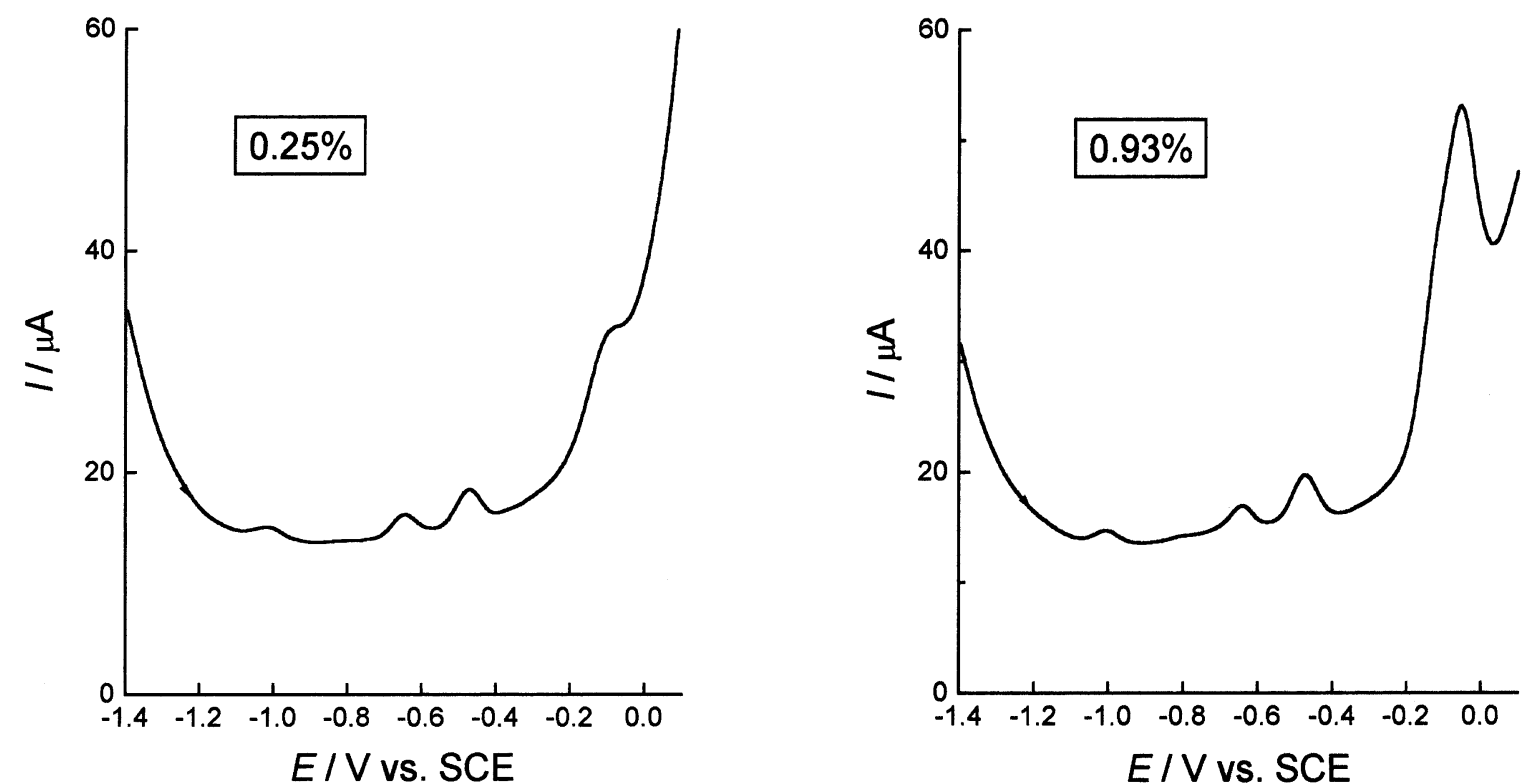

Fig. 1. BIA-SWASV traces for injection of $50 \mu \mathrm{l}$ of a sample containing $10^{-7} \mathrm{M} \mathrm{Zn}^{2+}, \mathrm{Cd}^{2+}, \mathrm{Pb}^{2+}$ and $\mathrm{Cu}^{2+}$ onto PCMTFE in $\mathrm{pH} 4.60 .1 \mathrm{M}$ acetate buffer (modifier dispersion 0.25 and $0.93 \%$ concentration, $1: 2$ water/acetone solvent). Deposition time 30 $\mathrm{s}$ at $-1.3 \mathrm{~V}$ vs. SCE, SW parameters: amplitude $25 \mathrm{mV}$; frequency $100 \mathrm{~Hz}$; potential increment $2 \mathrm{mV}$.

less in nitrate electrolyte than in acetate buffer, which means that oxygen can diffuse much more easily through the polymer film. The straight line portion at low frequency in nitrate electrolyte can be ascribed to charge separation within the polymer film again in agreement with [16]. This can be modelled by a capacitance, tak- ing into account roughness effects, in series with the $R C$ parallel combination describing the semicircle. Fitting of the experimental results for nitrate electrolyte gives $R=120 \Omega$ and $C=12 \mu \mathrm{F}$, and $0.25 \mathrm{mF}$ for the low frequency capacitance. For acetate buffer electrolyte $R=10 \mathrm{k} \Omega$ and $C=$ $15 \mu \mathrm{F}$.
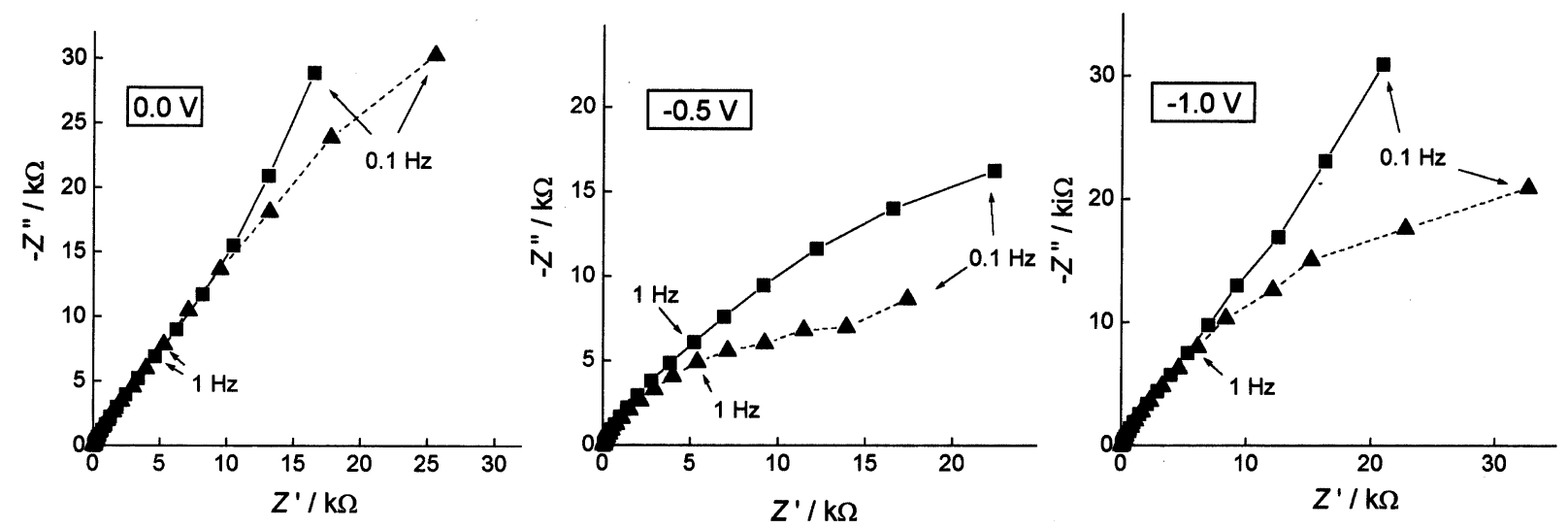

Fig. 2. Complex plane impedance plots for PESA-modified glassy carbon electrodes $(0.93 \%$ dispersion in $1: 2$ water/acetone solvent $)$ in $0.1 \mathrm{M}$ pH 4.6 acetate buffer, and $\boldsymbol{\Delta} 0.1 \mathrm{M} \mathrm{KNO}_{3} / 5 \mathrm{mM} \mathrm{HNO}_{3}$ electrolyte. 

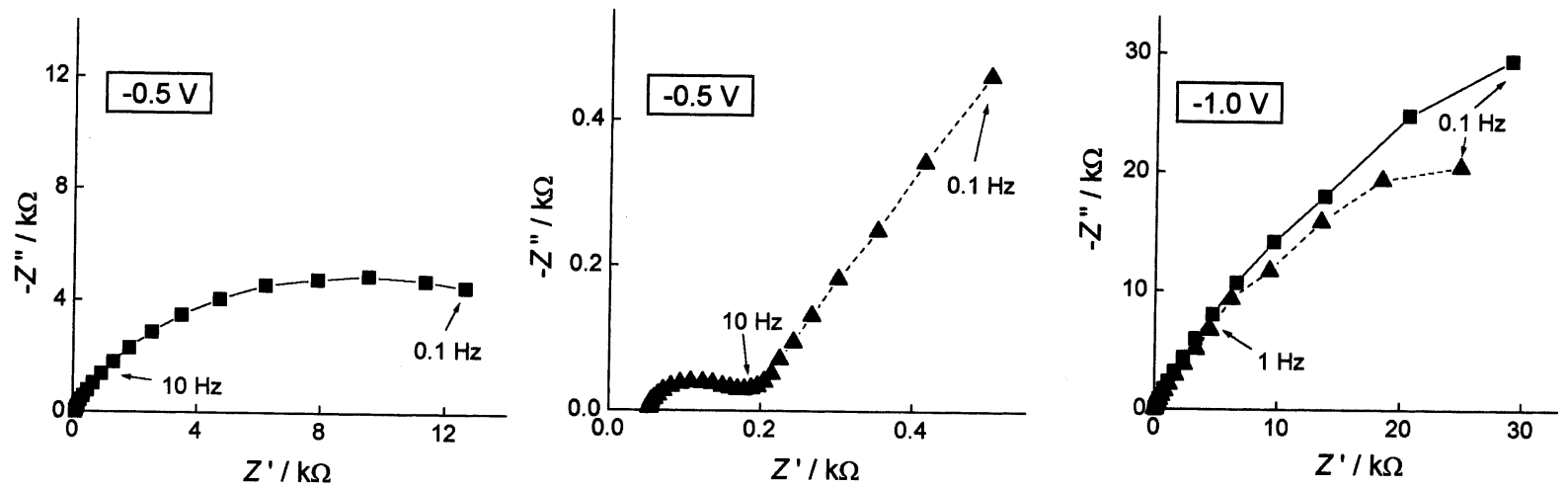

Fig. 3. Complex plane impedance plots for a PCMTFE (0.93\% dispersion in 1:2 water/acetone solvent) in $\mathbf{\square} 0.1 \mathrm{M} \mathrm{pH} 4.6$ acetate buffer, and $\boldsymbol{\Delta} 0.1 \mathrm{M} \mathrm{KNO}_{3} / 5 \mathrm{mM} \mathrm{HNO}_{3}$ electrolyte.

In Fig. 4 the responses in nitrate electrolyte at the PCMTFE formed from the three types of dispersion are compared. Some differences between the types of film are evident at $-0.5 \mathrm{~V}$, but there are essentially no differences at $-1.0 \mathrm{~V}$. At $-0.5 \mathrm{~V}$ the impedance is small and the semicircle which appears is attributed to oxygen reduction; additionally, the adsorption capacitances due to nitrate ion adsorption and permeation are of almost equal value. The high frequency semicircle $R$ and $C$ values are very similar for the two dispersions in 1:2 water/acetone solvent; however, for the 5:1 water/acetone solvent the values become
$R=300 \Omega$ and $C=50 \mu \mathrm{F}$. Thus, the general conclusion is that there is an influence from the concentration of the dispersion and the solvent. This influence must be on the morphology and structure of the film in such a way that the anions enter the film together with water solvent and cations, presumably swelling it to different extents, opening pores through which species can travel to the electrode substrate, and permitting the passage of oxygen. Such an effect will be less at more negative potentials when it will be more difficult for anions to enter the film, as observed at $-1.0 \mathrm{~V}$.
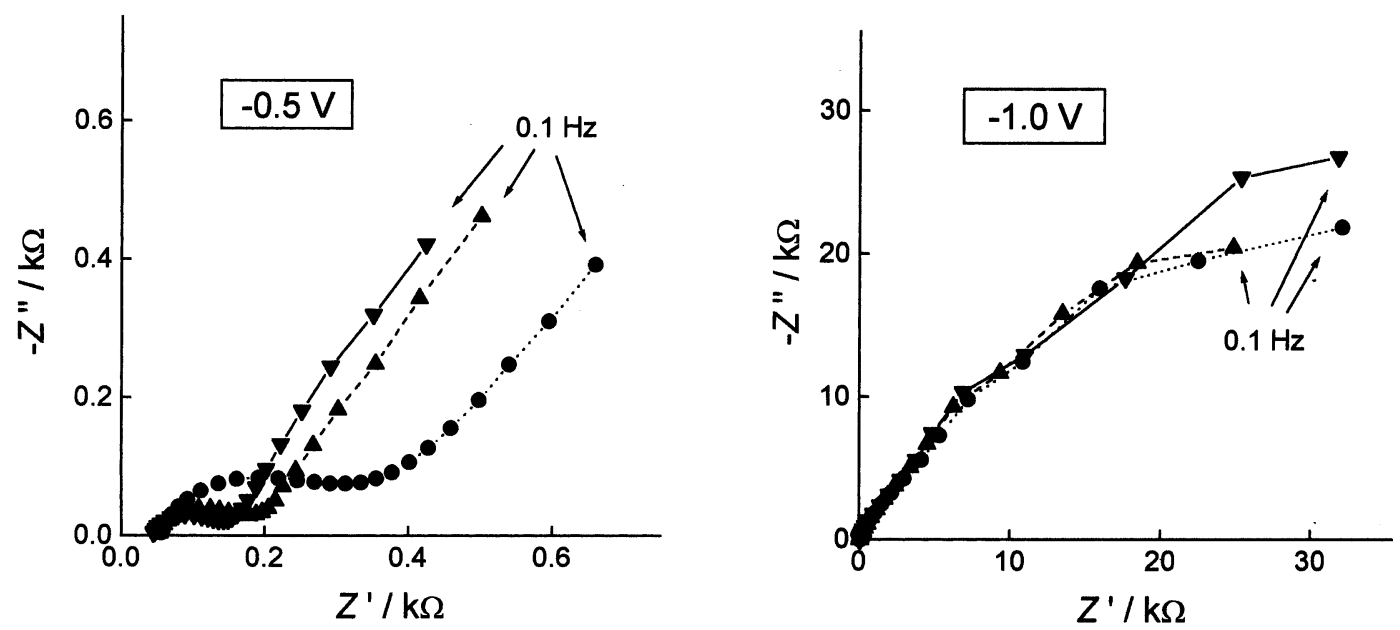

Fig. 4. Complex plane impedance plots for a PCMTFE in $0.1 \mathrm{M} \mathrm{KNO}_{3} / 5 \mathrm{mM} \mathrm{HNO}_{3}$ electrolyte: $\boldsymbol{\Delta} 0.93 \%$ in $1: 2$ water/acetone, $\boldsymbol{\nabla} 0.25 \%$ in $1: 2$ water acetone and $0.25 \%$ in $5: 1$ water/acetone solvent. 
The results presented in Figs. 2 and 3 can be re-examined in the light of these observations. Nitrate anion probably penetrates the film more easily during membrane swelling and opens up the structure in such a way as to permit the easier passage of oxygen. Although some influence from the different $\mathrm{pH}$ values could be expected, various studies have shown it not to be a significant parameter.

Thus, it is the identity of the electrolyte anion, rather than the composition of the modifier solution which has greatest effect on the film characteristics in the absence of electroactive species, except dissolved oxygen. The conclusion for ASV experiments-where the influence of oxygen should be excluded as much as possible-is that acetate buffer is to be preferred.

\subsection{BIA-SWASV experiments at PCMTFEs}

As mentioned above, Fig. 1 illustrates the stripping responses for a mixture of four heavy metal ions and shows the viability of the BIA-SWASV approach.

The influence of model surfactants was investigated for comparison with other polymermodified electrodes. These were Triton X-100 detergent, sodium dodecyl sulphate (SDS) polyelectrolyte and protein standard $\left(5.0 \mathrm{~g} \mathrm{dl}^{-1}\right.$

(a)

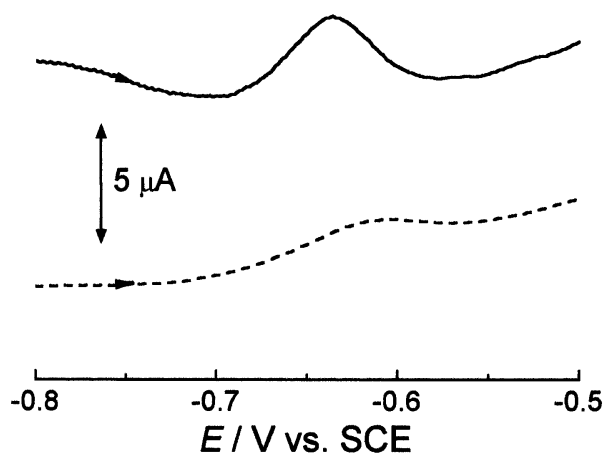

albumin and $3.0 \mathrm{~g} \mathrm{dl}^{-1}$ globulin, Sigma). Fig. 5 demonstrates the influence of Triton X-100 detergent on the height of the cadmium signal using a $0.93 \%$ film. Results from such experiments with all three types of surfactant are shown in the plots of Fig. 6. From these several deductions can be made:

- the stripping currents at PCMTFEs are lower than those at MTFEs by $\approx 30 \%$ (cadmium) and $70 \%$ (lead) in the absence of surfactants.

- There is generally a lesser alteration in the stripping current response at the PCMTFE with increasing surfactant concentration, in contrast to that at the MTFE. This partially reduces any negative effects due to the presence of the film.

- The behaviour of the PCMTFE on removing the surfactant (ensured by injecting blank electrolyte between successive injections of sample) shows no memory effect.

With respect to the last point, the data were registered using a procedure to ensure a clean surface without adsorbed species. This was done by injecting electrolyte between each injection of surfactant-containing sample, with application of a potential of $-0.3 \mathrm{~V}$ versus SCE for $10 \mathrm{~min}$. In normal analyses, it was found that a period of 1 min to is enough to remove any memory effect; however, for evaluation a longer period was em-
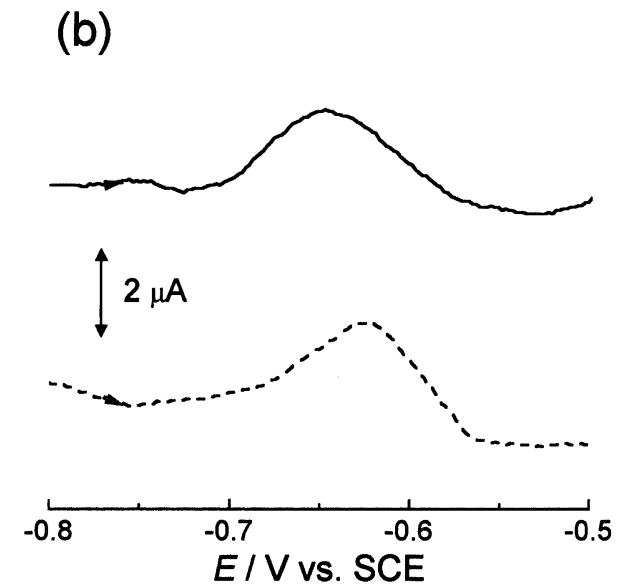

Fig. 5. BIA-SWASV traces showing influence of Triton X-100 on the height of the cadmium stripping signal at (a) MTFE (b) PCMTFE (0.93\% concentration, 1:2 water/acetone solvent) in the presence (-- -) and absence (-) of $1 \mathrm{mg} \mathrm{dm}^{-3} \mathrm{Triton} \mathrm{X}-100$. Experimental conditions as Fig. 1. 

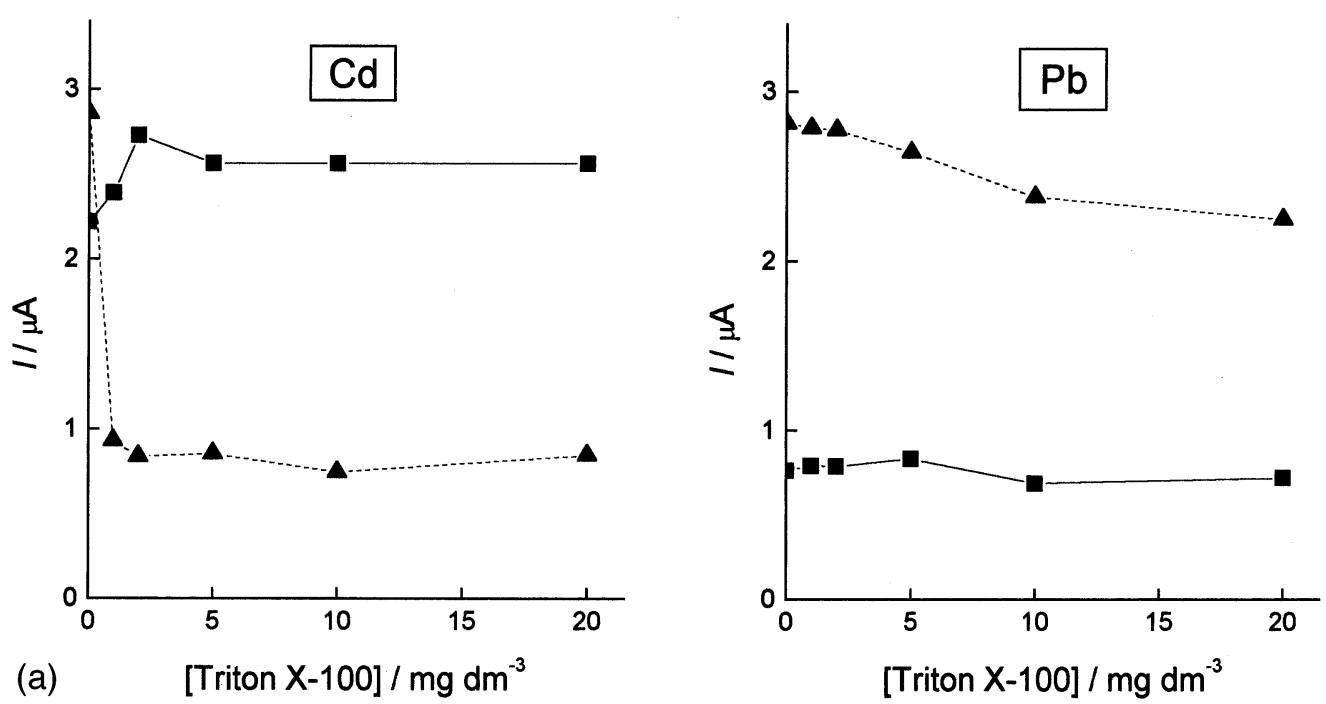

(a) $\quad\left[\right.$ Triton X-100]/ $\mathrm{mg} \mathrm{dm}^{-3}$

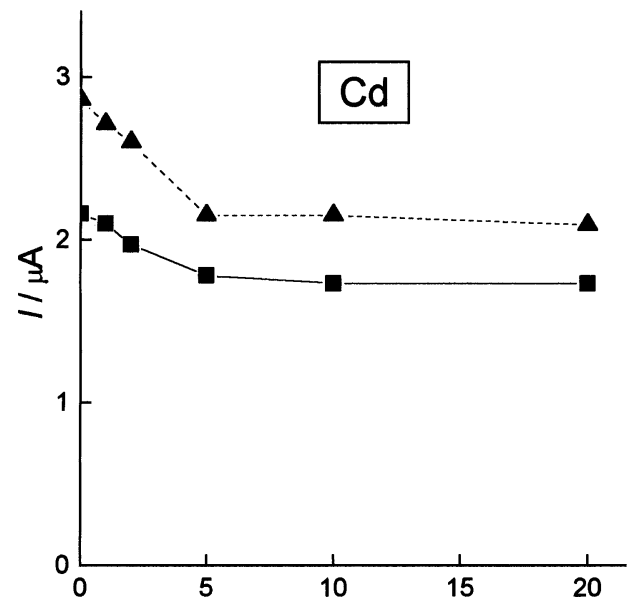

(b)

$[\mathrm{SDS}] / \mathrm{mg} \mathrm{dm}^{-3}$

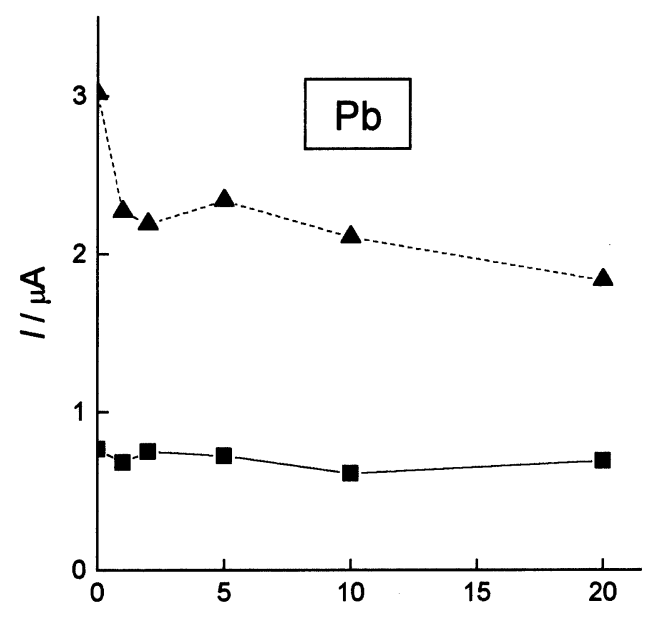

[SDS] $/ \mathrm{mg} \mathrm{dm}^{-3}$

Fig. 6. Plots showing influence of increasing surfactant concentration on stripping response at $\boldsymbol{\Delta}$ MTFE and $\boldsymbol{\square}$ PCMTFE $(0.93 \%$ in 1:2 water/acetone) for the BIA-SWASV of $10^{-7} \mathrm{M} \mathrm{Cd}^{2+}$ or $\mathrm{Pb}^{2+}$ : (a) Triton X-100; (b) sodium dodecylsulphate; (c) protein standard. Experimental conditions as Fig. 1.

ployed to be absolutely certain. If there were large amounts of copper ion in the solutions analysed then this procedure would not be sufficient, it being necessary to apply $+0.1 \mathrm{~V}$ for a short period. This was avoided when possible to ensure that there is no oxidation of the mercury film.

There is some variation in the stripping current obtained in the absence of surfactant at the PCMTFE. This has been noted previously for various different polymer coatings [17] and may be due partly to varying thickness of the films but to a greater extent to the internal structure of the film which is very difficult to control. In general the variation between different films is $<10 \%$. It suggests that the standard addition method is to be preferred for accurate measurements of concentration.

Calibration data for the three types of film from BIA-SWASV experiments for cadmium and lead are collected in Table 1. The data in Table 1 

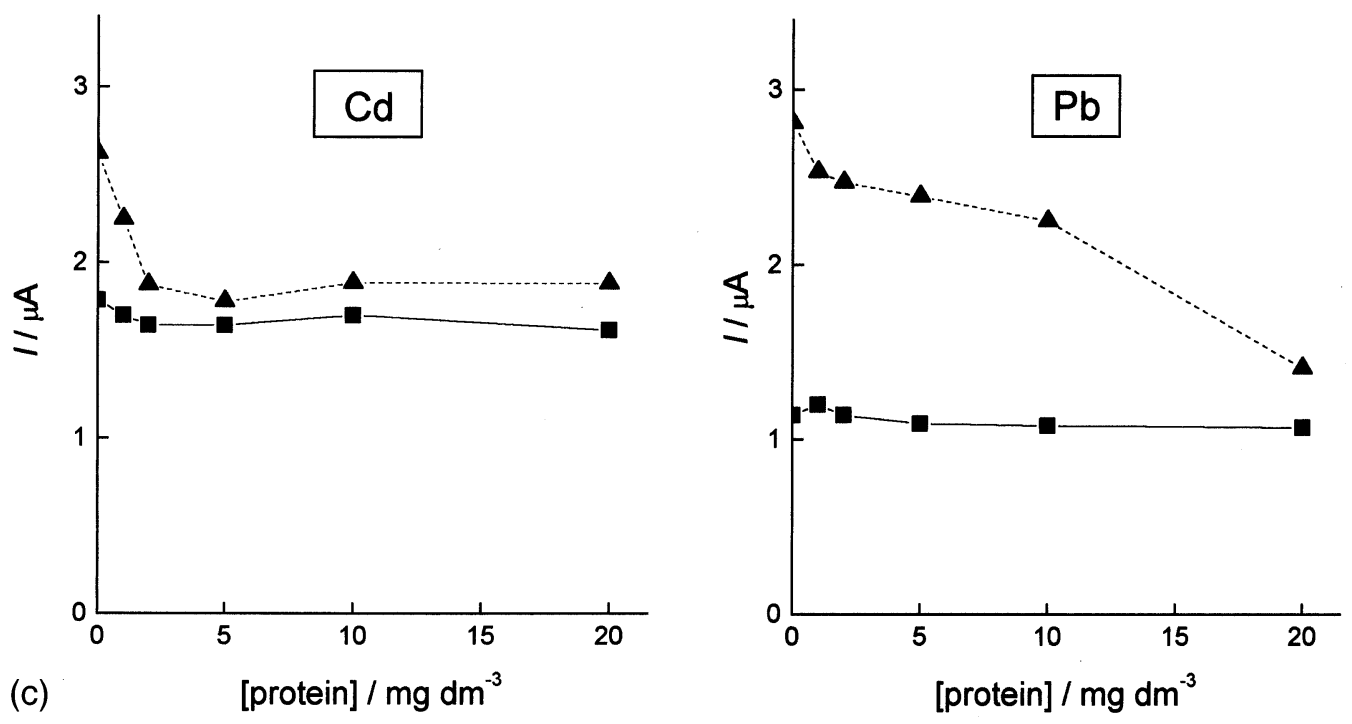

Fig. 6. (Continued)

were obtained over the range $10-100 \mathrm{nM}$; above $100 \mathrm{nM}$ the linearity begins to fall off. It can be seen that the film morphology and thickness have significant influence on the calibration plots, complementing the deductions from impedance experiments. In particular, the first two films show the influence of the film concentration. However, the thicker film (higher concentration in the dispersion) leads to higher BIA-SWASV signals. The reason for this can be traced to the more particulate nature of the film in the latter case, i.e. a more particulate film-forming dispersion, such that the cations can traverse the film more easily.
On increasing the ratio of water to acetone, however, there is a significant increase in signal and the lead signal becomes larger than the cadmium signal. This is slightly surprising since the lead is much larger than the cadmium cation. However, the more hydrophilic environment during film formation with 5:1 ratio water/acetone solvent almost certainly leads to different orientations between the neighbouring polymer chains than for the case of the 1:2 water/acetone ratio and may result in there being fewer sulphonate groups available to interact with the cations in an exchange mechanism. The data suggest that the best

Table 1

Results from calibration plots in the determination of lead and cadmium by BIA-SWASV at PCMTFEs in pH 4.6 acetate buffer

\begin{tabular}{|c|c|c|c|c|c|}
\hline Dispersion of PESA & & $\begin{array}{l}\text { Slope } \\
\left(\mu \mathrm{A} \mathrm{nM}^{-1}\right)\end{array}$ & Intercept $(\mu \mathrm{A})$ & $\begin{array}{l}\text { Correlation coefficient } \\
(n=6)(\%)\end{array}$ & $\begin{array}{l}\text { Detection limit }(3 \sigma) \\
(\mathrm{nM})\end{array}$ \\
\hline $\begin{array}{l}0.93 \% \text { in } 1: 2 \text { water } / \\
\text { acetone }\end{array}$ & Lead & $0.0106 \pm 0.0006$ & $0.0640 \pm 0.0248$ & 99.4 & 5.5 \\
\hline \multirow{2}{*}{$\begin{array}{l}0.25 \% \text { in } 1: 2 \text { water } / \\
\text { acetone }\end{array}$} & Cadmium & $0.00341 \pm 0.00092$ & $0.0124 \pm 0.0378$ & 99.5 & 3.4 \\
\hline & Lead & $0.00140 \pm 0.00021$ & $0.00243 \pm 0.00891$ & 99.6 & 5.9 \\
\hline \multirow{2}{*}{$\begin{array}{l}0.25 \% \text { in } 5: 1 \text { water/ } \\
\text { acetone }\end{array}$} & Cadmium & $0.0125 \pm 0.0005$ & $0.00652 \pm 0.02015$ & 99.7 & 3.7 \\
\hline & Lead & $0.0246 \pm 0.0010$ & $0.0893 \pm 0.0361$ & 99.7 & 3.8 \\
\hline
\end{tabular}


film is the last one, $0.25 \%$ in $5: 1$ water/acetone solvent. Detection limits are very similar in all cases at around $5 \mathrm{nmol} \mathrm{dm}^{-3}$.

It is interesting to compare these data with those obtained at Nafion-coated electrodes [4,5]. In that case, the currents at coated electrodes are higher but there is some influence of surfactants (a drop in signal of $\approx 20 \%$ up to $20 \mathrm{mg} \mathrm{dm}^{-3}$ ). Detection limits for the two types of coating are very similar. However, as noted previously [5], there appears to be a specific interaction between $\mathrm{Pb}^{2+}$ and non-ionic detergents (e.g. Triton), which leads to higher accumulations and larger stripping responses by up to $20 \%$, possibly via weak complex formation on the Nafion surface. Indeed, it may be that such electrochemical experiments offer a useful probe for these interactions. In analyses of effluents containing large but variable quantities of non-ionic detergents this influence in the response at Nafion-coated electrodes could be problematic in which case the use of PESA films would be a useful and viable alternative.

\section{Conclusions}

It has been demonstrated that PCMTFE coated mercury thin film electrodes can be used successfully in BIA with anodic stripping voltammetry. Characterization of films made from dispersions of different concentrations and in different solvent mixtures showed their importance in film optimisation. It was shown to be preferable to fill the cell with acetate buffer rather than nitrate electrolyte. Of the films tested, best results were obtained with a $0.93 \%$ dispersion concentration in 1:2 water/acetone solvent. Discrimination against model surfactants is excellent and the method provides a viable alternative to the use of Nafion coatings, particularly for application to samples containing large quantities of non-ionic detergents.

\section{Acknowledgements}

The support of Fundação para a Ciência e Tecnologia (FCT), Portugal, project PEAM/SEL/ 526/95, is gratefully acknowledged. D.A.F. thanks FAPESP, Brazil for a post-doctoral fellowship. The authors thank Professor J. Pingarron, Universidad Complutense de Madrid, for the gift of a sample of poly(ester sulphonic acid).

\section{References}

[1] J. Wang, Z. Taha, Anal. Chem. 63 (1991) 1053.

[2] C.M.A. Brett, A.M. Oliveira Brett, L.C. Mitoseriu, Electroanalysis 7 (1995) 225.

[3] C.M.A. Brett, A.M. Oliveira Brett, L. Tugulea, Anal. Chim. Acta 322 (1996) 151.

[4] C.M.A. Brett, A.M. Oliveira Brett, F.-M. Matysik, S. Matysik, S. Kumbhat, Talanta 43 (1996) 2015.

[5] C.M.A. Brett, D.A. Fungaro, J.M. Morgado, M.H. Gil, J. Electroanal. Chem. 468 (1999) 26.

[6] T. Gennett, W.C. Purdy, Anal. Chem. 62 (1990) 2155.

[7] J. Wang, Z. Lu, J. Electroanal. Chem. 266 (1989) 287.

[8] J. Wang, T. Golden, Anal. Chem. 61 (1989) 1397.

[9] J. Wang, Z. Taha, Electroanalysis 2 (1990) 383.

[10] J. Wang, D. Leech, M. Ozsoz, S. Martinez, M.R. Smyth, Anal. Chim. Acta 245 (1991) 139.

[11] L. Gorton, H.I. Karan, P.D. Hale, T. Inagaki, Y. Okamoto, T.A. Skotheim, Anal. Chim. Acta 228 (1990) 23.

[12] J. Wang, A.J. Reviejo, Anal. Chem. 65 (1993) 845.

[13] J. Wang, E. Dempsey, A. Eremenko, M.R. Smyth, Anal. Chim. Acta 279 (1993) 203.

[14] C.M.A. Brett, A.M. Oliveira Brett, Electrochemistry. Principles, Methods, and Applications, Oxford University Press, Oxford, 1993, pp. 244-248.

[15] P. Heiduschka, A.W. Munz, W. Göpel, Electrochim. Acta 39 (1994) 2207.

[16] E.K. Umnikrishnan, S.D. Kumar, B. Maiti, J. Membr. Sci. 137 (1997) 133.

[17] M.E.R. Dam, K.N. Thomsen, P.G. Pickup, K.H. Schrøder, Electroanalysis 7 (1995) 70. 